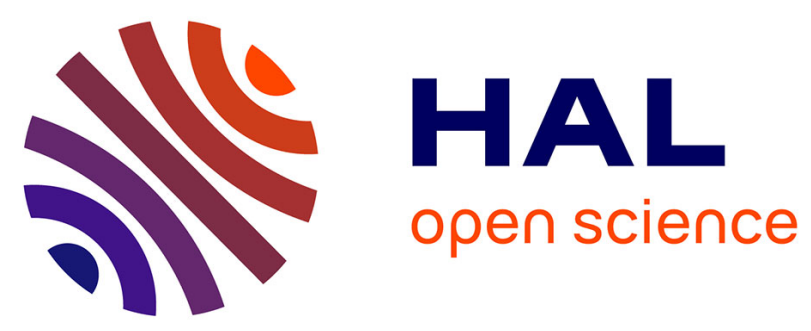

\title{
Conductivity of Manganite Films under the Action of Tension Caused by the Deformation of Substrate
}

\author{
G. Ovsyannikov, T. Shaikhulov, V. Shakhunov, A. Klimov, V. \\ Preobrazhenskii, Nicolas Tiercelin, Philippe Pernod
}

\section{- To cite this version:}

G. Ovsyannikov, T. Shaikhulov, V. Shakhunov, A. Klimov, V. Preobrazhenskii, et al.. Conductivity of Manganite Films under the Action of Tension Caused by the Deformation of Substrate. Physics of the Solid State, 2019, 61 (9), pp.1665-1669. 10.1134/S1063783419090208 . hal-02318290

\author{
HAL Id: hal-02318290 \\ https://hal.science/hal-02318290
}

Submitted on 11 Oct 2020

HAL is a multi-disciplinary open access archive for the deposit and dissemination of scientific research documents, whether they are published or not. The documents may come from teaching and research institutions in France or abroad, or from public or private research centers.
L'archive ouverte pluridisciplinaire HAL, est destinée au dépôt et à la diffusion de documents scientifiques de niveau recherche, publiés ou non, émanant des établissements d'enseignement et de recherche français ou étrangers, des laboratoires publics ou privés. 


\title{
Conductivity of Manganite Films under the Action of Tension Caused by the Deformation of Substrate
}

\author{
G. A. Ovsyannikov ${ }^{a, *}$, T. A. Shaikhulov ${ }^{a}$, V. A. Shakhunov ${ }^{a}$, A. A. Klimov ${ }^{a, c}$, \\ V. L. Preobrazhenskii ${ }^{b}$, N. Tiercelin ${ }^{c}$, and P. Pernod ${ }^{c}$ \\ ${ }^{a}$ Kotelnikov Institute of Radio Engineering and Electronics, Russian Academy of Sciences, Moscow, Russia \\ ${ }^{b}$ Prokhorov General Physics Institute, Russian Academy of Sciences, Moscow, Russia \\ ${ }^{c}$ University of Lille, CNRS, Centrale Lille, ISEN, Univ. Valenciennes, UMR 8520-IEMN, F-59000 Lille, France \\ *e-mail: gena@hitech.cplire.ru
}

Received April 15, 2019; revised April 22, 2019; accepted April 24, 2019

\begin{abstract}
The electron transport properties of strained thin $\mathrm{La}_{0.7} \mathrm{Ba}_{0.3} \mathrm{MnO}_{3}$ (LBMO) epitaxial films are studied. Films $40-100 \mathrm{~nm}$ in thickness were prepared by laser ablation at a temperature $T=700-800^{\circ} \mathrm{C}$ in pure oxygen atmosphere of $0.3-1 \mathrm{mBar}$. Ferroelectric crystal substrates (011)0.79 $\mathrm{PbMg}_{1 / 3} \mathrm{Nb}_{2 / 3} \mathrm{O}_{3}-$ $0.21 \mathrm{PbTiO}_{3}(\mathrm{PMN}-\mathrm{PT})$ with a Curie temperature of $150^{\circ} \mathrm{C}$ and high piezoelectric constants were used to create a mechanical stress. The ferroelectric polarization and piezoelectric effects on the electrical parameters of LBMO films are studied.
\end{abstract}

Keywords: epitaxial manganite films, laser ablation, piezoelectric

DOI: $10.1134 / \mathrm{S} 1063783419090208$

\section{INTRODUCTION}

A change in magnetic parameters of rare-earth manganite perovskite films having structure $\mathrm{Re}_{1-x} \mathrm{~A}_{x} \mathrm{MnO}_{3}$ (Re are rare-earth elements, such as $\mathrm{La}$ or $\mathrm{Nd}$, and $\mathrm{A}$ are alkaline-earth metals, such as $\mathrm{Sr}$, $\mathrm{Ca}$, and $\mathrm{Ba}$ ) is due to mechanical strain caused by the mismatch of lattice parameters of a film and a substrate [1-6]. It was found that the three-dimensional compression of a crystal lattice increases the amplitude of jump probability in the double exchange model, which increases the Curie temperature $\left(T_{\mathrm{C}}\right)$, whereas biaxial Jahn-Teller distortions increase the localization of electrons and decrease $T_{\mathrm{C}}$ [7-10]. Although the magnetic and resistive parameters are closely related within the framework of a double exchange model, there is no clarity in the mechanism for changing the resistive properties of epitaxial manganite films during the deformation. At the same time, the control of resistive states of epitaxial manganite films via deformations is of interest to develop straintronics [11-13].

Manganite films, whose Curie temperature $T_{\mathrm{C}}$ is close to room temperature, is especially attractive for practical purposes. The ferromagnetic phase transition for a single-phase $\mathrm{La}_{0.7} \mathrm{Ba}_{0.3} \mathrm{MnO}_{3}$ (LBMO) crystal proceeds under $T_{\mathrm{C}}=345 \mathrm{~K}$ [14-17]. Giant magnetostriction (up to $4 \times 10^{-4}$ ) was observed in a LBMO single crystal at a temperature close to Curie one [18]. The magnetic and resistive properties of epitaxial
LBMO films are significantly changed during the growth on different substrates due to the deformation effect of a film lattice caused by substrate [19-21].

The electronic transport parameters of $\mathrm{La}_{0.7} \mathrm{Ba}_{0.3} \mathrm{MnO}_{3}$ (LBMO) epitaxial manganite films grown on a (011) $0.79 \mathrm{~Pb}\left(\mathrm{Mg}_{1 / 3} \mathrm{Nb}_{2 / 3}\right) \mathrm{O}_{3}-0.21 \mathrm{PbTiO}_{3}$ (PMN-PT) piezoelectric substrate, which provides film deformation controllable with electric field, are experimentally studied in this work.

\section{EXPERIMENTAL SAMPLES}

$\mathrm{La}_{0.7} \mathrm{Ba}_{0.3} \mathrm{MnO}_{3}$ epitaxial films $40-150 \mathrm{~nm}$ in thickness were deposited onto $(011) 0.79 \mathrm{~Pb}\left(\mathrm{Mg}_{1 / 3} \mathrm{Nb}_{2 / 3}\right) \mathrm{O}_{3}-$ $0.21 \mathrm{PbTiO}_{3}$ substrates $5 \times 5 \times 0.3 \mathrm{~mm}$ in size by laser ablation under $600-800^{\circ} \mathrm{C}$ and oxygen pressure of $0.2-0.5 \mathrm{mBar}$. The targets were prepared from a mixture of $\mathrm{La}_{2} \mathrm{O}_{3}, \mathrm{BaCO}_{3}$, and $\mathrm{MnCO}_{3}$ powders via ceramic technology. The stoichiometric composition of the mixture was used to perform the synthesis. In the pseudocubic representation, the lattice parameter of LBMO with the stoichiometric composition of the target by oxygen appeared to be $a_{L}=0.390 \mathrm{~nm}$. An impurity in the target $\left(\mathrm{BaMnO}_{3}\right)$ was $2.5 \%$ [20]. Ferroelectric crystals (PMN-PT) have saturation polarization $P_{r}=30-35 \mathrm{C} / \mathrm{cm}^{2}$, low coercive field, and high piezoelectric constants $d_{33}=1500 \mathrm{pC} / \mathrm{N}$, $d_{32}=-1883 \mathrm{pC} / \mathrm{N}$, and $d_{31}=610 \mathrm{pC} / \mathrm{N}[21,22]$. 


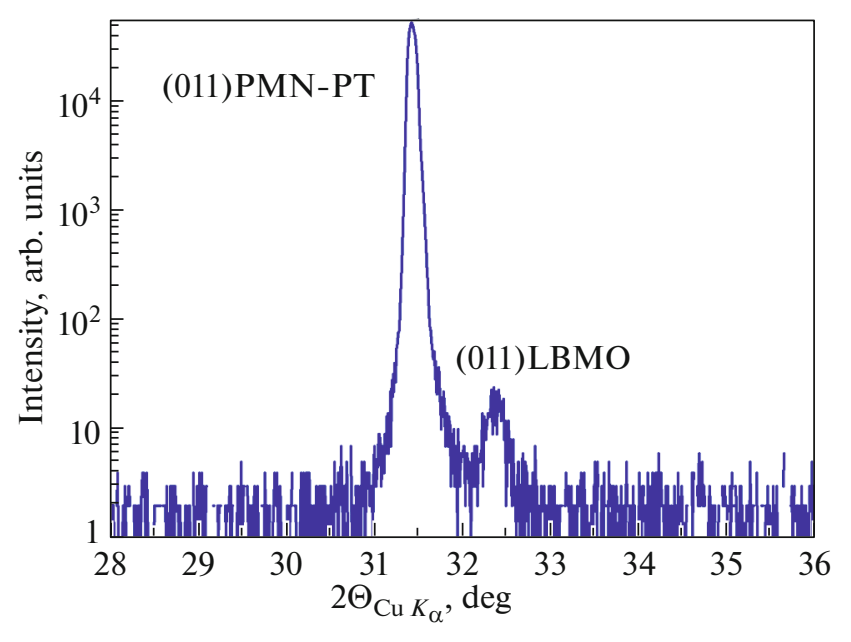

Fig. 1. $2 \Theta / \omega$ diffractogram of $\mathrm{La}_{0.7} \mathrm{Ba}_{0.3} \mathrm{MnO}_{3}$ film deposited on (011) $\mathrm{PbMg}_{1 / 3} \mathrm{Nb}_{2 / 3} \mathrm{O}_{3}-\mathrm{PbTiO}_{3}$ substrate.

The crystallographic parameters of the films and substrates were found on a 4-circle $X$-ray diffractometer by measurements of X-ray diffractograms in $2 \Theta / \omega$ mode and $\varphi$-scanning and by measuring the rocking curves. The grown LBMO films were oriented both relative to the normal to the substrate plane and relative to the selected direction in the substrate plane. The interplanar spacing parameter in LBMO films along the normal to the substrate plane and the constant of lattice of a substrate were found from $2 \Theta / \omega X$-ray diffraction patterns. The section $2 \Theta / \omega$ on a diffractogram of a $\mathrm{La}_{0.7} \mathrm{Ba}_{0.3} \mathrm{MnO}_{3}$ film deposited on a substrate (011) $\mathrm{PbMg}_{1 / 3} \mathrm{Nb}_{2 / 3} \mathrm{O}_{3}-\mathrm{PbTiO}_{3}$ (Fig. 1) shows that PMN-PT has a perovskite structure close to a cube with lattice constants $a_{S}=0.403 \mathrm{~nm}$, whereas a constant of the lattice of the LBMO film is $a_{L}=$ $0.391 \mathrm{~nm}$. The film grows according to the epitaxial relationship of (011)LBMO//(011)PMN-PT, [100] $\mathrm{LBMO} / /[100] \mathrm{PMN}-\mathrm{PT}$. The stress values arising in the film in the plane of the substrate along the direction of [100] $\varepsilon_{100 \mid}=\left(a_{S}-a_{L}\right) / a_{L}$ without electric voltage on the PMN-PT substrate is $3.1 \%$.

\section{ELECTROPHYSICAL PARAMETERS}

The resistance of the films was studied with a fourpoint method, eliminating the influence of contact resistance. The contact pads were prepared by cathode sputtering of platinum through a metal mask. The front of the substrate sputtered with a LBMO film was as a top electrode. A silver paste was applied to the back side of the substrate (Fig. 2). Electrical bias voltage (about $100 \mathrm{~V}$ ) was applied normally to the substrate. The film resistance was measured by setting the current in the substrate plane.

A peak at $T=T_{\mathrm{m}}$, which is the insulator-metal transition temperature (Fig. 3), is observed on the

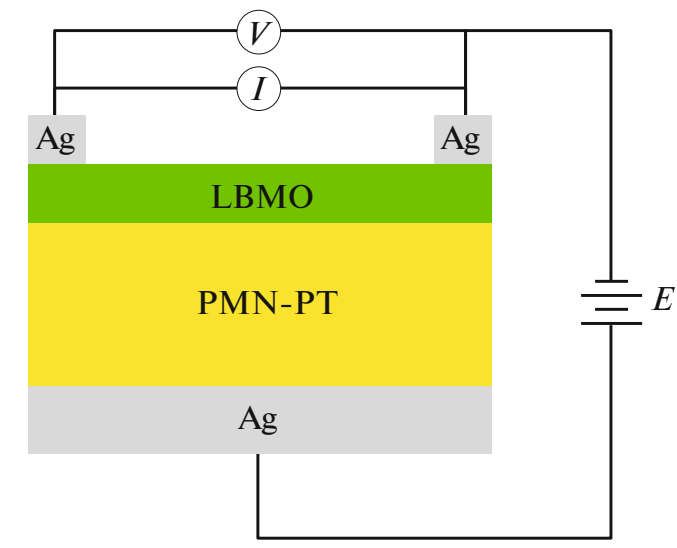

Fig. 2. A scheme for measuring dependence of resistance of LBMO film on electric field applied to (011)PMN-PT substrate. $I$ is the current source for measuring the resistance, $V$ the voltage meter for measuring the resistance, and $E$ the high voltage source on the substrate causing its deformation.

temperature dependences of LBMO film resistance without electric voltage on the substrate with a decrease in temperature below room temperature. In addition, there is anisotropy of resistance in the direction of current flow. The measurements were performed after preliminary polarization of the substrate with a voltage higher than $100 \mathrm{~V}$, which slightly changes the shape of temperature dependence of the resistance $R(T)$. A decrease in resistance at $T \leq T_{\mathrm{m}}$ is probably due to an increase in area of the conducting ferromagnetic regions. The resistivity of all samples increases under low temperatures $(T<100 \mathrm{~K})$. The $T_{\mathrm{m}}$ temperature in $\mathrm{La}_{1-x} \mathrm{Ba}_{x} \mathrm{MnO}_{3}$ crystals with a lower amount of $\mathrm{Ba}(x \leq 0.2)$ is several dozen degrees lower than in those having optimal composition $(x=0.3)$, and when $T<T_{\mathrm{m}}$, the resistance of LBMO films increases [23]. The resistance at low temperatures in films with an optimal amount of $\mathrm{Ba}(x=0.3)$ is due to scattering of carriers on impurities and defects and depends on the intensity of the electron-electron and electron-magnon interactions [20]. In high temperature region $T>T_{\mathrm{m}}$, the temperature dependence of resistance of manganite films is due to activation processes [24].

The deformation of the PMN-PT substrate was measured on a strain gauge glued to the PMN-PT substrate [21], which give the relative deformation of the substrate. No absolute deformation of the substrate was measured. Only relative changes are important. A tensile deformation of the substrate $(1000 \mathrm{ppm})$ in the [0 11] PMN-PT direction is observed in the sample at a field strength equal to coercive force of the ferroelectric loop both at positive $E_{c^{+}}=2 \mathrm{kV} / \mathrm{cm}$ and negative $E_{c^{-}}=-2 \mathrm{kV} / \mathrm{cm}$ field direction. The compression deformation along the [100] direction of 


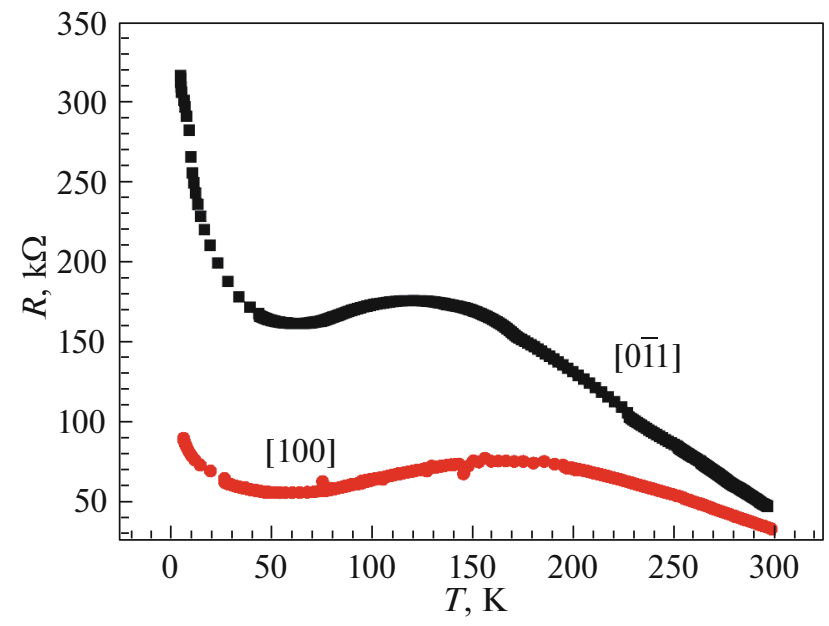

Fig. 3. Temperature dependences of resistance measured with two directions of current flow in $\mathrm{La}_{0.7} \mathrm{Ba}_{0.3} \mathrm{MnO}_{3}$ film deposited on (011) $\mathrm{PbMg}_{1 / 3} \mathrm{Nb}_{2 / 3} \mathrm{O}_{3}-\mathrm{PbTiO}_{3}$ substrate.

PMN-PT is substantially less (about 500 ppm) and is also observed under electric field strength equal to coercive force, although there is an asymmetry by the sign of the electric field (Fig. 4a). The deformation peaks of the substrate upon field strength near the coercive force are probably due to rotation of a ferroelectric polarization vector $[25,26]$. The asymmetry of the peaks relative to the direction of the electric field is due to measurement type of the resistance of the LBMO film and due to the contribution of current spreading in the transverse direction to the direction measured. It should be noted that there is no substrate deformation in the direction [0 11] PMN-PT without electric field. Therefore, there should be no resistive states in the LBMO film without the field.

The measurement results of a relationship between change in resistance of the LBMO film and the strength of electric field for two directions of current flow [0 $\overline{1} 1$ ] LBMO and [100] LBMO are shown in Fig. $4 \mathrm{~b}$. It is clear that the change in resistance of the LBMO film corresponds to the substrate deformation: there is a large change in resistance of the film measured at the current along the [0 $\overline{1} 1]$ LBMO direction upon field strength near the coercive force. The strongest change in resistance of the LBMO film is observed for the [0 $\overline{1} 1]$ direction upon electric field strength equal to the coercive force of a ferroelectric loop. The results are in agreement with the dependences of deformations of the substrate in the [0 $\overline{1} 1]$ and [001] directions on the electric field strength (Fig. 4a). The maximum change in resistance (3\%) is comparable to that observed in other studies [27, 28].

A change in resistance of the LBMO film may be explained by the double exchange model [29], within
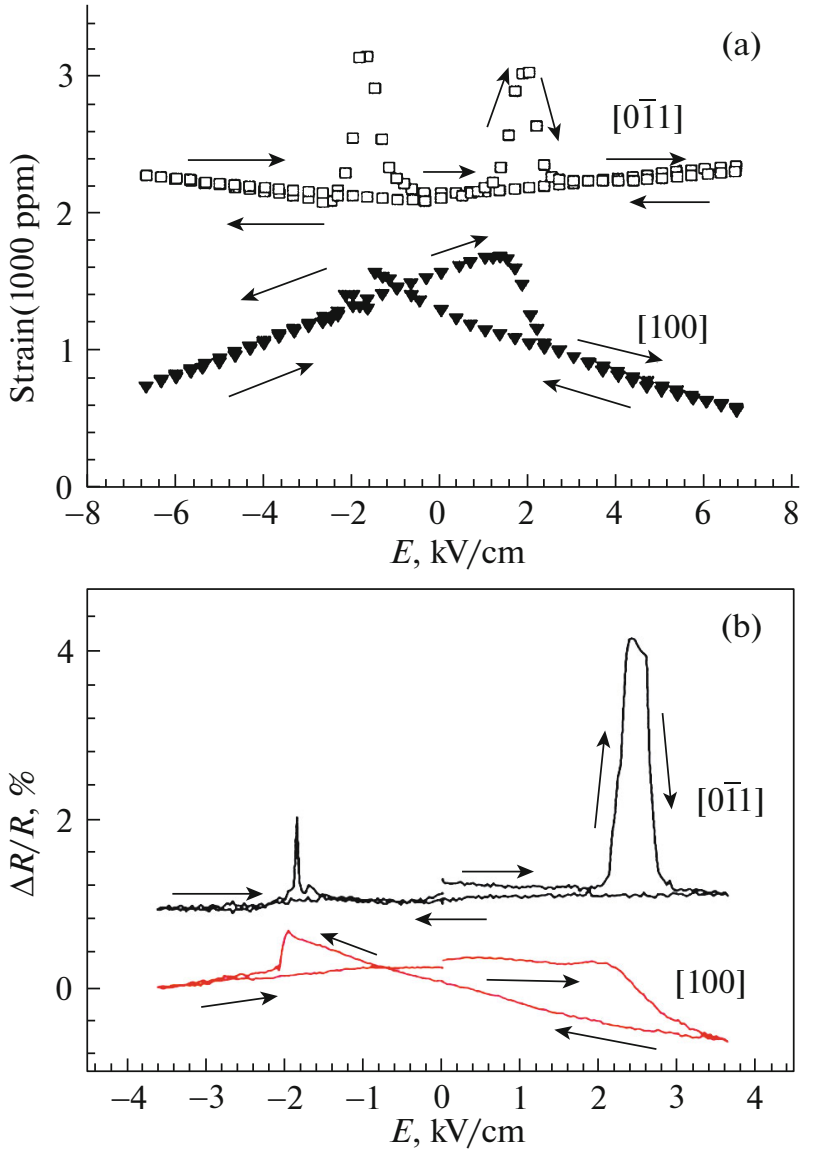

Fig. 4. (a) Deformation of (011)PMN-PT substrate measured in the [0 111] PMN-PT and [100] PMN-PT directions and (b) dependence of resistance of $\mathrm{La}_{0.7} \mathrm{Ba}_{0.3} \mathrm{MnO}_{3}$ film on the applied electric field strength for two directions of current flow. The curves are shifted along the ordinate for clarity. A change in both deformation and resistance is important. ( $E$ varied in the range from 0 to $4 \mathrm{kV} / \mathrm{cm}$, then from 4 to $-4 \mathrm{kV} / \mathrm{cm}$, and from -4 to $0 \mathrm{kV} / \mathrm{cm}$.)

which a strong dependence of resistance on film strength should be observed. The tunneling between $\mathrm{Mn}^{3+}$ and $\mathrm{Mn}^{4+}$ states depends on a distance between $\mathrm{Mn}$ and $\mathrm{O}$. This distance is changed due to stretching of the LBMO film, which increases the distance of $\mathrm{Mn}-\mathrm{O}$ bonds and decreases the jump length of an interaction between $\mathrm{Mn}^{3+}$ and $\mathrm{Mn}^{4+}$ states, increasing the resistance $[10,29]$. It was shown that strong electron-phonon interaction, which is due to Jahn-Teller splitting of outer Mn orbitals, plays a role besides double exchange mechanism [10].

There are several states with different resistances (A, B, and C in Fig. 5) upon asymmetric electric field sweeping from $-4 \mathrm{kV} / \mathrm{cm}$ to one of the three maximum values of positive electric field $E_{\max }=2.38,2.47$, and $2.51 \mathrm{kV} / \mathrm{cm}$. When there is no electric field, the resistance of the LBMO $(\Delta R / R)$ film remains unchanged. This state is to be "reset," when the elec- 


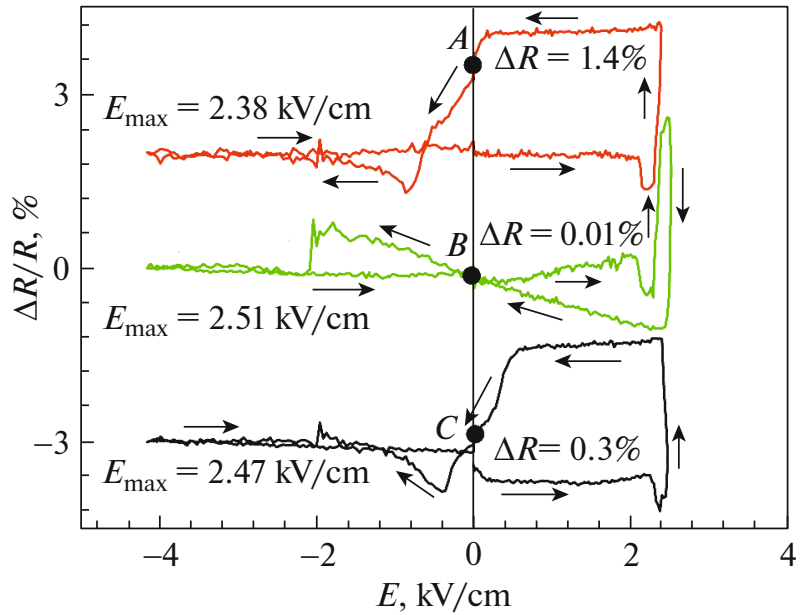

Fig. 5. Relationship between film resistance and electric field strength during asymmetric sweeping for three maximum positive electric field values $E_{\max }=2.38,2.47$, and $2.51 \mathrm{kV} / \mathrm{cm}$. Measurements were performed during current flows along the [0 $\overline{1} 1]$ LBMO direction. The curves are shifted along the ordinate for clarity. Relative changes in both deformation and resistance are important. ( $E$ varied in the range from 0 to $4 \mathrm{kV} / \mathrm{cm}$, then from 4 to -4 and from -4 to $0 \mathrm{kV} / \mathrm{cm}$.)

tric field is negative $(4 \mathrm{kV} / \mathrm{cm})$. The resistive state upon maximum change in resistance of the film $\Delta R / R=1.4 \%$ is observed upon maximum positive electric field strength $E_{\max }$ being slightly less than $E_{c^{+}}$. When $E_{\max }$ values are high, the resistance value of resistive state either decreases to fractions of a percent or is absent. A similar case is typical with asymmetric sweeping of the electric field in the negative direction. The $\Delta R / R$ value during negative sweep is substantially less due to the asymmetry of resistance dependence on the field (Fig. 4b). This behavior of the resistive parameters of the LBMO film may be explained by ferroelectric repolarization of the [0 11] PMN-PT domains around the isomorphic phase boundary [2628]. When the field is applied along [100], similar states are substantially smaller in amplitude and poorly reproducible.

In general, there is an initial state of resistance of LBMO film indicated as "B" (Fig. 5), which does not depend on voltage exceeding the coercive force in both the positive and negative directions. In the case of asymmetric sweeping, there are also two other states designated as " $A$ " and " $C$ " (Fig. 5), which have resistance differed from "B" states. All three states are achieved by varying the amplitude of the electric-field sweep.

\section{CONCLUSIONS}

There is anisotropy of resistance in the epitaxial LBMO films deposited on a (011) PMN-PT substrate due to crystallographic anisotropy of the grown (110) LBMO film. There was a peak of resistance at $T=T_{\mathrm{m}}$, typical of manganites, on the temperature dependences of resistance of LBMO films without substrate tension with a decrease in temperature below room temperature. The resistance of all samples increases at low temperatures $(T<100 \mathrm{~K})$, which is due to lower amount of $\mathrm{Ba}$ than in the substrate. The resistance is changed by about $3 \%$ during the symmetric sweep of the electric field strength relative to a zero value near coercive force. There are stable resistive states, which can be switched by changing the amplitude of electric field variation, during the asymmetric sweeping on the dependence of film resistance on the field.

\section{ACKNOWLEDGMENTS}

The authors are grateful to N.V. Andreev, K.I. Constantinian, A.M. Petrzhik, E.A. Sviridova, and A.V. Shadrin for their assistance and useful discussion of the results.

\section{FUNDING}

This work was performed within the framework of State task and was partially supported by the Russian Foundation for Basic Research (projects 16-29-14022 and 19-07-00143) and the International Laboratory LEMAC-LICS.

\section{CONFLICT OF INTEREST}

There are no conflicts of interest to declare.

\section{REFERENCES}

1. A.-M. Haghiri-Cosnetand and J. P. Renard, J. Phys. D 36, R127 (2003).

2. Zh. Huang, G. Y. Gao, Zh. Zh. Yin, X. X. Feng, Y. Zh. Chen, X. R. Zhao, J. R. Sun, and W. B. Wu, J. Appl. Phys. 105, 113919 (2009).

3. G. A. Ovsyannikov, A. M. Petrzhik, I. V. Borisenko, A. A. Klimov, Yu. A. Ignatov, V. V. Demidov, and S. A. Nikitov, J. Exp. Theor. Phys. 108, 48 (2009).

4. P. R. Sagdeo, N. P. Lalla, A. V. Narlika, D. Prabhakaran, and A. T. Boothroyd, Phys. Rev. B 78, 174106 (2008).

5. P. Orgiani, A. Guarino, C. Aruta, C. Adamo, A. Galdi, A. Yu. Petrov, R. Savo, and L. Maritato, J. Appl. Phys. 101, 033904 (2007).

6. P. Murugavel, T. W. Noh, and J. G. Yoon, J. Appl. Phys. 95, 2536 (2004).

7. Y. Lu, J. Klein, C. Hofener, B. Wiedenhorst, J. B. Philipp, F. Herbstritt, A. Marx, L. Alff, and R. Gross, Phys. Rev. B 62, 15806 (2000).

8. Y. Chen, B. G. Ueland, J. W. Lynn, G. L. Bychkov, S. N. Barilo, and Y. M. Mukovskii, Phys. Rev. B 78, 212301 (2008).

9. F. Tsui, M. C. Smoak, T. K. Nath, and C. B. Eom, Appl. Phys. Lett. 76, 2421 (2000).

10. A. J. Millis, T. Darling, and A. Migliori, J. Appl. Phys. 83, 1588 (1998). 
11. V. Iurchuk, B. Doudin, B. Kundys, and D. Multistate, J. Phys.: Condens. Matter 26, 292202 (2014).

12. Y. Lee, Z. Q. Liu, J. T. Heron, J. D. Clarkson, J. Hong, C. Ko, M. D. Biegalski, U. Aschauer, S. L. Hsu, M. E. Nowakowski, J. Wu, H. M. Christen, S. Salahuddin, J. B. Bokor, N. A. Spaldin, D. G. Schlom, and R. Ramesh, Nat. Commun. 6, 5959 (2015).

13. Y. Yang, Z. L. Luo, M. M. Yang, H. Huang, H. Wang, J. Bao, G. Pan, C. Gao, Q. Hao, S. Wang, M. Jokubaitis, W. Zhang, G. Xiao, Y. Yao, Y. Liu, and X. G. Li, Appl. Phys. Lett. 102, 33501 (2013).

14. H. L. Ju, J. Gopalakrishnan, J. L. Peng, Qi Li, G. C. Xiong, T. Venkatesan, and R. L. Greene, Phys. Rev. B 51, 6143 (1995).

15. K. Rogacki, X. Xiong, P. W. Klamut, R. Dybzinski, J. Shaffer, J. D. Jorgensen, and B. Dabrowski, Phys. Rev. B 58, 2716 (1998).

16. H. L. Ju, Y. S. Nam, J. E. Lee, and H. S. Shin, J. Magn. Magn. Mater. 1, 219 (2000).

17. S. L. Yuan, C. S. Xiong, Z. Y. Li, Z. C. Xia, G. Q. Zhang, G. Peng, F. Tu, Y. P. Yang, J. Liu, L. Liu, and Y. H. Xiong, J. Phys.: Condens. Matter 14, 173 (2002).

18. R. V. Demin, L. I. Koroleva, A. Z. Muminov, and Ya. M. Mukovskii, Phys. Solid State 48, 322 (2006).

19. H. Tanaka, T. Kanki, J.-H. Choi, T. Kawai, and J. Zhang, Phys. Rev. B 64, 184404 (2001).

20. G. A. Ovsyannikov, T. A. Shaikhulov, V. A. Shakhunov, V. V. Demidov, N. V. Andreev, A. E. Pestun, and V. L. Preobrazhenskii, Phys. Solid State 59, 2198 (2017).
21. G. A. Ovsyannikov, T. A. Shaikhulov, V. A. Shakhunov, V. L. Preobrazhensky, T. Mathurin, N. Tiercelin, and P. Pernod, J. Supercond. Nov. Magn. 14, 173 (2019).

22. Feifei Wang, Laihui Luo, Dan Zhou, Feifei Wang, Laihui Luo, and Dan Zhou, Appl. Phys. Lett. 90, 212903 (2007).

23. J. Zhang, H. Tanaka, T. Kanki, J.-H. Choi, and T. Kawai, Phys. Rev. B 64, 184404 (2001).

24. N. G. Bebenin, R. I. Zainullina, V. V. Mashkautsan, V. V. Ustinov, and Ya. M. Mukovskii, Phys. Rev. B 69, 104434 (2004).

25. T. X. Nan, Z. Y. Zhou, J. Lou, M. Liu, X. Yang, Y. Gao, S. Rand, and N. X. Sun, Appl. Phys. Lett. 100, 132409 (2012).

26. T. Wu, P. Zhao, M. Bao, A. Bur, J. L. Hockel, K. Wong, K. P. Mohanchandra, C. S. Lynch, and G. P. Carman, J. Appl. Phys. 109, 124101 (2011).

27. Weiping Zhou, Yuanqiang Xiong, Zhengming Zhang, Dunhui Wang, Weishi Tan, Qingqi Cao, Zhenghong Qian, and Youwei Du, ACS Appl. Mater. Interface 8, 5424 (2016).

28. R. K. Zheng, Y. Jiang, Y. Wang, H. L. W. Chan, C. L. Choy, and H. S. Luo, Phys. Rev. B 79, 174420 (2009).

29. N. G. Bebenin, R. I. Zainullina, and V. V. Ustinov, Phys. Usp. 61, 719 (2018).

Translated by A. Tulyabaev 